\title{
Efeitos da adubação nitrogenada e potássica no crescimento da cultura da cana-de-açúcar segunda soca
}

\section{Effect of nitrogen and potassium fertilization on the growth of the second ratoon of sugarcane}

\author{
Alefe Bastos*, João Teodoro, Marconi Teixeira, Edson da Silva, Diego Costa e Murilo Bernardino \\ Instituto Federal Goiano Campus Rio Verde, Departamento de hidráulica e irrigação, CEP: 75901-970, Rio Verde-G0, Brasil \\ ( ${ }^{\star}$ E-mail: alefe viana@hotmail.com) \\ http://dx.doi.org/10.19084/RCA17052
}

Recebido/received: 2017.03 .02

Aceite/accepted: 2017.04.13

\section{R E S U M O}

O objetivo deste estudo foi o de avaliar a influência da adubação nitrogenada e potássica sobre algumas variáveis biométricas da cultura da cana-de-açúcar segunda soca. O experimento foi conduzido em vasos, contendo Latossolo Vermelho distrófico, implantados numa área experimental do Instituto Federal Goiano Campus Rio Verde, GO. O delineamento experimental utilizado foi o de blocos casualizados, com três repetições, analisado em esquema fatorial $2 \times 5$, cujos tratamentos foram, com e sem adubação nitrogenada ( 0 e $120 \mathrm{~kg}$ de N/ha), combinados com cinco doses de potássio $\left(0,60,120,180\right.$ e $\left.240 \mathrm{~kg} \mathrm{ha}^{-1}\right)$. As variáveis biométricas altura de planta, comprimento e número de folhas, número de plantas, comprimento e diâmetro do colmo, número de colmo e comprimento médio do colmo foram determinadas aos 150, 190, 230 e 270 dias após o corte. A adubação nitrogenada aumentou o comprimento das folhas, porém limitou a quantidade por planta. Já para o comprimento médio dos colmos e altura de plantas somente houve incrementos com uso do nitrogênio sem a presença da adubação potássica. O potássio proporcionou incrementos para altura

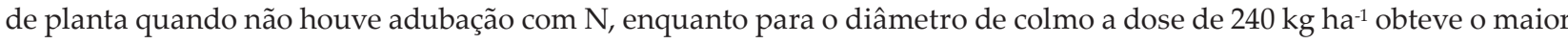
valor quando associado à adubação nitrogenada.

Palavras-chave: biometria, latossolo vermelho distrófico, nitrogênio, potássio.

\section{A B S T R A C T}

The objective of this study was to evaluate the influence of nitrogen and potassium fertilization on some biometric variables of the second sugarcane ratoon. The experiment was conducted in pots containing Dystrophic Red Latosol, implanted in an experimental area of the Goiano Federal Institute Campus Rio Verde, GO. The experimental design was a randomized block design, with three replications, analyzed in a $2 \times 5$ factorial scheme, being that treatments was with and without nitrogen fertilization ( 0 e $120 \mathrm{~kg}$ of $\mathrm{N} / \mathrm{ha})$, combined with five potassium rates $(0,60,120,180$ and $240 \mathrm{~kg} \mathrm{ha}^{-1}$ ). The biometric variables plant height, leaf length and number, number of plants, stalk length and diameter, stalk number and mean stalk length were determined at 150, 190, 230 and 270 days after the cut. The application of nitrogen increased leaf length, but limited the amount of leaves per plant. As for the average stalk length and plant height, there were only increases with nitrogen use without the presence of potassium fertilization. Potassium yielded increases in plant height when there was no fertilization with $\mathrm{N}$, while for the stalk diameter the $240 \mathrm{~kg}^{-1} \mathrm{dose}^{-}$ obtained the highest value when associated with nitrogen fertilization.

Keywords: biometry, dystroferric red latosol, nitrogen, potassium. 


\section{INTRODUÇÃO}

A cana-de-açúcar é atualmente uma cultura de crescente importância econômica, considerada uma das principais commodities agrícolas em termos de produtividade (Devos, 2010), cultivada em regiões de clima tropical ou subtropical, utilizada principalmente para produção de açúcar e biocombustível (Kajihara, 2012).

O Brasil é o maior produtor mundial de cana-de-açúcar de forma que na última safra 2015/16 a produção nacional foi de 665,58 milhões de toneladas. São Paulo, maior produtor, é responsável por $55,23 \%$ da produção, seguido por Goiás com $11,00 \%$. A produtividade média para a atual temporada da safra 2015/16 foi de 76,90 $\mathrm{t} \mathrm{ha}^{-1}$, tendo um aumento de $9,1 \%$ comparada a safra anterior de 2014/15 (CONAB, 2016). Esse incremento, está ligado a estudos do crescimento e desenvolvimento da cana-de-açúcar interagidos com fatores genéticos da planta, do clima e solo do local, sob o manejo antrópico.

A adubação é uma das mais importantes práticas no manejo da cana-de-açúcar para que se obtenha elevados níveis de produtividade, e isso pode ser estudado através de uma análise de crescimento (Gava et al., 2011), a qual, pode ser realizada através de amostragens temporais de biomassa da parte aérea ou através de índices fisiológicos e biométricos determinados durante todo o ciclo de crescimento da cultura. A grande importância dos parâmetros biométricos em condições de campo, é que através dessas informações pode obter-se conhecimentos do desenvolvimento da cultura. A parte aérea da cultura da cana-de-açúcar pode ser dividida em três etapas de desenvolvimento: fase inicial (crescimento lento), fase de crescimento rápido (surgimento e alongamento de internódios dos colmos, na qual acumula se cerca de $75 \%$ da matéria seca) e fase final ou de maturação (Robertson et al., 1996; Gava et al., 2001; Inman-Bamber et al., 2002; Franco, 2008; Oliveira, 2011).

O potássio é um nutriente de extrema importância para as plantas, pois está envolvido nos processos de perfilhamento, crescimento vegetativo e aumento do teor de carboidratos, óleos, lipídeos e proteínas; auxilia na fixação do nitrogênio; promove o armazenamento de açúcar e amido; influencia a resistência à seca e geada, pois regula a utilização da água, além de obter grande importância na fase de maturação e frutificação das plantas (Aquino et al., 1993).

De acordo com a lei n. 15.834 de 23 de novembro de 2006, que está vigente no Brasil, até o ano 2028 toda a área cultivada deve ser colhida mecanicamente, eliminando totalmente a colheita por despalha a fogo. No sistema de colheita mecanizada sem queima, as folhas, bainhas, ponteiro, além de quantidade variável de pedaços de colmo são cortados, triturados e lançados sobre a superfície do solo, formando uma cobertura de resíduo vegetal (mulch) denominada palha ou palhada (De Souza et al., 2005). De acordo com Christoffoleti et al. (2007), a produtividade de palha que fica sobre o solo varia de 10 a $30 \mathrm{t} \mathrm{ha}^{-1}$, mantendo níveis elevados de matéria orgânica no atual sistema de cultivo. A resposta da cana-de-açúcar às adubações, principalmente relacionado ao $\mathrm{N}$ é bastante influenciado pela palhada que fica no solo, pois a mineralização deste material (matéria orgânica) disponibiliza grandes quantidades de $\mathrm{N}$ para a cultura. De acordo com Vieira-Megda et al. (2015) a cana-de-açúcar acumula em média na palhada $73,14 \mathrm{t} \mathrm{ha}^{-1}$, quando é realizado adubações com $100 \mathrm{~kg} \mathrm{ha}^{-1}$ de $\mathrm{N}$, e todo esse $\mathrm{N}$ presente nesse material orgânico potencialmente com a colheita mecanizada pode retornar ao solo e ser aproveitado pelos ciclos subsequentes da cana-de-açúcar.

Com este trabalho pretendeu-se estudar o efeito da adubação nitrogenada e potássica sobre algumas variáveis biométricas durante a fase de crescimento da cultura da cana-de-açúcar segunda soca.

\section{MATERIAL E MÉTODOS}

O experimento foi conduzido no período compreendido de abril de 2015 a janeiro de 2016, em vasos plásticos com dimensões de 0,6 m (diâmetro) × $0,80 \mathrm{~m}$ (altura) preenchidos com pedra brita n. 2 $(0,1 \mathrm{~m})$ e uma mistura de solo com esterco bovino separadamente, compondo uma camada de $0,60 \mathrm{~m}$ de profundidade, com o propósito de se aproximar dos solos utilizados para o cultivo de cana-de-açúcar com colheita mecanizada, sendo esses ricos em matéria orgânica, proveniente da palhada que fica sobre o solo. A composição química do esterco 


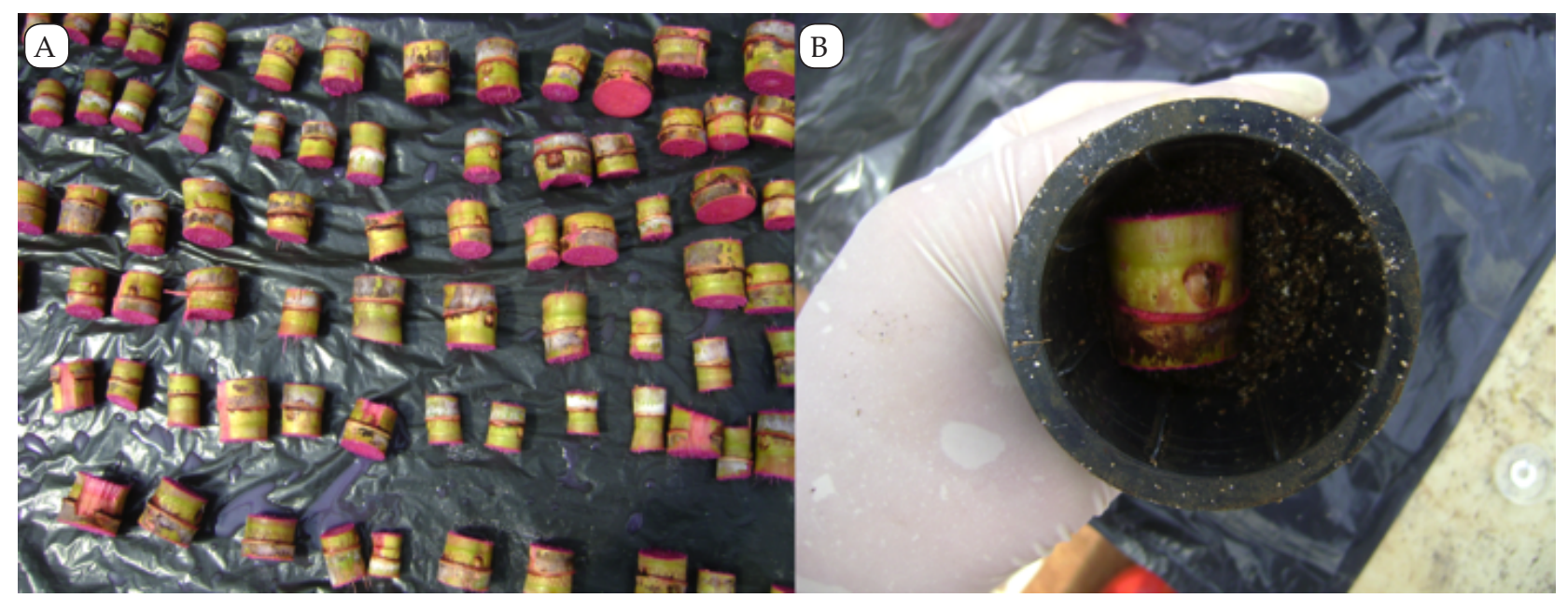

Figura 1 - Gemas axilares de cana-de-açúcar (A); Tubete contendo 1 (uma) gema axilar (B).

utilizado foi a seguinte: $\mathrm{N}=12 \mathrm{~g} \mathrm{~kg}^{-1}, \mathrm{P}=9 \mathrm{~g} \mathrm{~kg}^{-1}$, $\mathrm{K}=18 \mathrm{~g} \mathrm{~kg}^{-1}, \mathrm{Ca}=17 \mathrm{~g} \mathrm{~kg}^{-1}$ e $\mathrm{Mg}=4 \mathrm{~g} \mathrm{~kg}^{-1}$. Os vasos foram dispostos em céu aberto em uma área experimental pertencente ao Instituto Federal Goiano Campus Rio Verde, GO, Brasil, situado na latitude $17^{\circ} 48^{\prime} 2^{\prime \prime} \mathrm{S}$ e longitude $50^{\circ} 53^{\prime} 57^{\prime \prime} \mathrm{O}$, com altitude média de 720 metros. O clima da região é classificado conforme Köppen (Castro Neto, 1982), como Aw (tropical), com chuva nos meses de outubro a maio, e com seca de junho a setembro. A temperatura média anual varia de $20 \mathrm{a} 35^{\circ} \mathrm{C}$ e as precipitações pluviométricas variam de 1.500 a $1.800 \mathrm{~mm}$ anuais.

O plantio da cana-de-açúcar foi realizado no dia 15 de outubro de 2013, em tubetes contendo vermiculite com substrato (Figura 1). O método utilizado para o estabelecimento da cultura foi o MPB (muda pré-brotada), o que torna necessário o transplantio de mudas para os vasos. O transplantio foi realizado 15 dias após o plantio (DAP). Foi utilizada a variedade IACSP95-5000, que possui como característica produção agrícola muito alta, indicada para ambientes favoráveis (A1 - C2), porte muito ereto, ótima brotação de soqueira, apresentando bom perfilhamento e fechamento de entrelinhas, alto florescimento, e ainda apresentando resistência as principais doenças. A colheita foi realizada no dia 13/08/2014 iniciando o segundo (primeira soca) ciclo da cultura, na qual foi colhido no dia 06/04/2015 dando início ao terceiro (segunda soca) ciclo da cultura, em que se constitui o estudo em questão.

No experimento foi utilizado solo coletado de um
Latossolo Vermelho distrófico (Solos, 2013) juntamente com esterco bovino curtido, sendo uma proporção 3:1 v/v, respectivamente. As características químicas do substrato (solo + esterco) utilizadas nos vasos são observadas no Quadro 1.

\section{Delineamento experimental e caracterização dos tratamentos}

O delineamento experimental utilizado foi o de blocos casualizados, com três repetições, analisado em esquema fatorial $2 \times 5$, na qual os tratamentos foram, com e sem adubação nitrogenada ( 0 e $120 \mathrm{~kg}$ de $\mathrm{N} / \mathrm{ha}$ ), combinados com cinco doses de potássio $\left(0,60,120,180\right.$ e $240 \mathrm{~kg} \mathrm{ha}^{-1}$, equivalentes para vaso).

\section{Condições experimentais}

Todas as adubações com nitrogênio e potássio foram realizadas em cobertura de forma manual de acordo com os devidos tratamentos (Figura 2). As coberturas de nitrogênio $(60 \mathrm{~kg}$ de $\mathrm{N}$ por cobertura) foram aplicadas aos 45 e 90 dias após o corte (DAC) na forma de ureia.

As cobertura de potássio (30,60, 90 e $120 \mathrm{~kg}$ de $\mathrm{K}_{2} \mathrm{O}$ por cobertura) foram igualmente efetuadas aos 45 e 90 DAC na forma de cloreto de potássio. Também foi realizada uma adubação de $2 \mathrm{~kg} \mathrm{ha}^{-1}$ de Boro na forma de ácido bórico, aos 45 dias DAC via solução em todos os tratamentos. 
Quadro 1 - Caracterização química iniciais do solo + esterco bovino utilizado nos vasos, antes do estabelecimento de cada ciclo

\begin{tabular}{|c|c|c|c|c|c|c|c|c|c|}
\hline \multirow{6}{*}{ 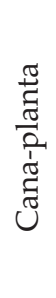 } & $\mathrm{pH}$ & K & $\mathrm{Ca}$ & $\mathrm{Mg}$ & $\mathrm{Al}$ & SB & \multirow{3}{*}{$\begin{array}{l}\text { CTC } \\
198,8 \\
\end{array}$} & \multirow{3}{*}{$\begin{array}{l}\text { M. O. } \\
\mathrm{g} \mathrm{dm}^{-3} \\
51\end{array}$} & \multirow{3}{*}{$\begin{array}{c}\mathrm{N} \text { (total) } \\
\mathrm{mg} \mathrm{kg}^{-1} \\
4326\end{array}$} \\
\hline & \multicolumn{2}{|l|}{$\mathrm{CaCl}_{2}$} & \multicolumn{4}{|c|}{ } & & & \\
\hline & 6,9 & 14,5 & 139 & 33 & $<1$ & 186,9 & & & \\
\hline & $\mathrm{m}$ & $\mathrm{V}$ & \multirow[t]{2}{*}{$\mathrm{P}$} & $\mathrm{S}$ & $\mathrm{Cu}$ & $\mathrm{Fe}$ & $\mathrm{Mn}$ & \multirow[t]{2}{*}{ B } & \multirow{2}{*}{-} \\
\hline & \multicolumn{2}{|c|}{ 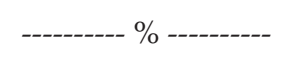 } & & \multicolumn{4}{|c|}{ - } & & \\
\hline & 0 & 94 & 305 & 70 & 4,8 & 38 & 8,6 & 0,33 & - \\
\hline \multirow{6}{*}{ 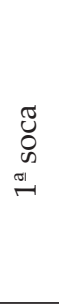 } & $\mathrm{pH}$ & $\mathrm{K}$ & $\mathrm{Ca}$ & $\mathrm{Mg}$ & $\mathrm{Al}$ & SB & \multirow[t]{2}{*}{ CTC } & \multirow{3}{*}{$\begin{array}{c}\text { M. O. } \\
\text { g dm }^{-3} \\
45\end{array}$} & \multirow{3}{*}{$\begin{array}{c}\mathrm{N} \text { (total) } \\
\mathrm{mg} \mathrm{kg}^{-1} \\
3938\end{array}$} \\
\hline & $\mathrm{CaCl}_{2}$ & & \multicolumn{4}{|c|}{ } & & & \\
\hline & 6,7 & 1,8 & 121 & 33 & $<1$ & 153,3 & 169,9 & & \\
\hline & $\mathrm{m}$ & $\mathrm{V}$ & $\mathrm{P}$ & $\mathrm{S}$ & $\mathrm{Cu}$ & $\mathrm{Fe}$ & $\mathrm{Mn}$ & \multirow[t]{2}{*}{ B } & \multirow{2}{*}{ - } \\
\hline & \multicolumn{2}{|c|}{ 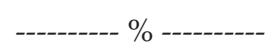 } & & \multicolumn{4}{|c|}{-1--- } & & \\
\hline & 0 & 91 & 241 & 4 & 5,5 & 52 & 10,1 & 0,16 & - \\
\hline \multirow{6}{*}{$\begin{array}{l}\tilde{J} \\
0 \\
0 \\
\text { ñ } \\
\text { v }\end{array}$} & $\mathrm{pH}$ & $\mathrm{K}$ & $\mathrm{Ca}$ & $\mathrm{Mg}$ & $\mathrm{Al}$ & SB & \multirow[t]{2}{*}{ CTC } & \multirow{3}{*}{$\begin{array}{l}\text { M. O. } \\
\text { g dm }^{-3} \\
42\end{array}$} & \multirow{3}{*}{$\begin{array}{c}\mathrm{N} \text { (total) } \\
\mathrm{mg} \mathrm{kg}^{-1} \\
3619\end{array}$} \\
\hline & $\mathrm{CaCl}_{2}$ & & \multicolumn{4}{|c|}{ - mmolc dm ${ }^{-3}$ - } & & & \\
\hline & 6,7 & 1,9 & 119 & 30 & $<1$ & 150,9 & 165,6 & & \\
\hline & $\mathrm{m}$ & $\mathrm{V}$ & $\mathrm{P}$ & $\mathrm{S}$ & $\mathrm{Cu}$ & $\mathrm{Fe}$ & $\mathrm{Mn}$ & \multirow[t]{2}{*}{ B } & \multirow{3}{*}{$\begin{array}{l}- \\
-\end{array}$} \\
\hline & ------- & ----- & & ----- & $---r$ & 3 ------ & ------- & & \\
\hline & 0 & 91 & 236 & 5 & 5,3 & 47 & 10,3 & 0,18 & \\
\hline
\end{tabular}

P - Fósforo; S - Enxofre; K - Potássio; Ca - Cálcio; Mg - Magnésio; Al - Alumínio; SB - Soma das Bases; CTC - Capacidade de Troca Catiônica; V - Saturação por Bases; M. O. - Matéria Orgânica; B - Boro; Cu - Cobre; Fe - Ferro; Mn - Manganês; Zn - Zinco; m - Saturação de Alumínio.

Durante o período experimental foram aplicadas todas as formas de manejo necessárias para o controle de plantas daninhas, pragas e doenças, bem como outros fatores que poderiam comprometer o adequado desenvolvimento das plantas de cana-de-açúcar.

A irrigação foi manejada pelo método de lisímetro de drenagem, onde foram utilizados quatro vasos para cada repetição, totalizando doze vasos (lisímetros). Estes eram colocados na capacidade de campo as 18:00 horas e a água drenada coletada 12 horas após. Após a coleta do volume drenado dos seis vasos, os dados eram aplicados na equação 1 , para se chegar à capacidade de campo de cada vaso. Os vasos de referência (lisímetro) também receberam a cultura e os tratamentos correspondentes a cada linha de gotejadores. Todas as irrigações foram realizadas no período da manhã.

$\mathrm{CC}=\mathrm{AP}-\mathrm{AD}$

Em que:
$\mathrm{CC}=$ Capacidade de campo;

$\mathrm{AP}=$ Volume de água aplicada;

$\mathrm{AD}=$ Volume de água drenada.

A quantidade de água a ser aplicada era sempre proporcional à quantidade suficiente para elevar a umidade à capacidade de campo.

A irrigação foi realizada, utilizando-se gotejadores, de fluxo turbulento com vazões de $1,65 \mathrm{~L} \mathrm{~h}^{1}$ a 1,0 bar, espaçados em $0,50 \mathrm{~m}$, sendo instalados uma linha lateral de gotejadores para cada tratamento, totalizando seis linhas de gotejo. Um filtro de disco de 100 mesh foi utilizado para a retirada de partículas sólidas que porventura pudessem entrar no sistema.

\section{Variáveis analisadas}

As variáveis biométricas foram determinadas aos 150, 190, 230 e 270 DAC, de forma que a última data 


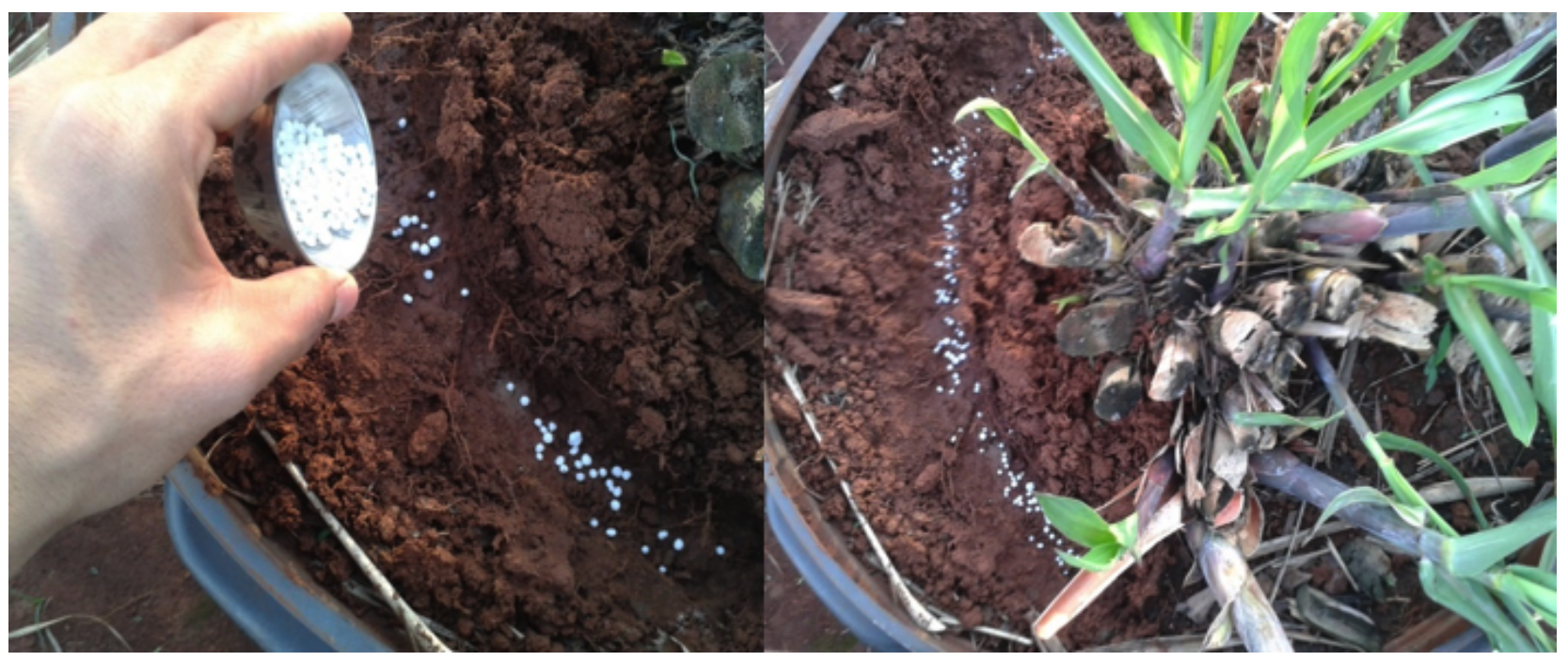

Figura 2 - Aplicação de nitrogênio na cultura da cana-de-açúcar.

compreendeu o dia da colheita. As variáveis foram as seguintes: altura de planta (AP), comprimento de folha (CF), número de folhas (NF), número de plantas (NP) comprimento do colmo (CCO), diâmetro do colmo (DC), comprimento médio do colmo (CMC), e número de colmos (NC). A altura de planta, comprimento de folha e comprimento do colmo foram determinadas com o auxílio de uma fita métrica. A AP foi mensurada, a partir do solo até o colarinho da folha +1 , enquanto o NC foi determinado através de contagem manual, DC foi determinado com o auxílio de um paquímetro digital e o CMC foi obtido através da divisão do CCO pelo NC.

\section{Análises estatísticas}

Os dados foram submetidos a análise de variância. Para os fatores com e sem adubação nitrogenada, quando Teste F foi significativo, realizou-se o teste de médias de Tukey a 0,05 de probabilidade. Para os fatores doses de potássio realizou-se análise de regressão polinomial linear e quadrática; quando não houve diferença para nenhuma das equações estudadas ou quando o coeficiente de determinação não alcançou o valor mínimo de $65 \%$, foi considerado como não ajuste das equações. Utilizou-se o software estatístico SISVAR-ESAL ${ }^{\circledR}$ (Ferreira, 2011) e para os ajustes dos modelos e confecção dos gráficos, foi utilizado o aplicativo computacional SigmaPlot@11 (Systat Software Inc.).

\section{RESULTADOS E DISCUSSÃO}

Nos quadros de 2 a 5, estão presentes somente as variáveis que foram influenciadas por algum fator, nessas datas de avaliação. Observando o Quadro 2, notamos que aos $150 \mathrm{DAC}$, a variável AP foi influenciada estatisticamente pela adubação potássica, porém nenhuma das equações estudadas se ajustaram a esse fator analisado. As variáveis $C F$ e DC foram influenciadas pela interação entre os fatores $\mathrm{N} \times \mathrm{K}$. Quando realizado o desdobramento em função das doses de potássio dentro de cada nível de $\mathrm{N}$, para o comprimento de folha e diâmetro de colmo, constatou-se que nenhuma das equações estudadas se ajustaram.

Aos $150 \mathrm{DAC}$, o fator $\mathrm{N}$ isolado influenciou significativamente as variáveis NF e NP, sendo que quando na presença da adubação nitrogenada a variável NF obteve valores inferiores comparado aos tratamentos que não receberam adubação nitrogenada, obtendo em média 0,8 folhas a menos. Resultados divergentes foram encontrados por Freitas et al. (2013), na qual afirma que quanto maior a dose de nitrogênio maior foi o número de folhas, porém indiferente da época de avaliação. Para a variável NP os tratamentos com a presença da adubação nitrogenada foram superiores aos tratamentos que não receberam $\mathrm{N}$, obtendo um aumento em média de 6 plantas (Quadro 2). Em estudo avaliando os parâmetros biométricos da cana-de-açúcar em função de diferentes níveis 
Quadro 2 - Análise de variância para altura de planta (AP), comprimento de folha (CF), número de folhas (NF), número de plantas (NP) e diâmetro do colmo (DC) da cana-de-açúcar, aos 150 dias após o corte (DAC), submetida a diferentes tratamentos com e sem nitrogênio e a diferentes doses de adubação potássica

\begin{tabular}{|c|c|c|c|c|c|c|}
\hline \multirow{2}{*}{ FV } & \multirow{2}{*}{ GL } & \multicolumn{5}{|c|}{ Quadrado médio } \\
\hline & & AP & $\mathrm{CF}$ & NF & NP & DC \\
\hline $\mathrm{N}$ & 1 & $120,00^{\text {ns }}$ & $76,80^{*}$ & $4,80^{*}$ & $300,83^{* *}$ & $0,03^{\text {ns }}$ \\
\hline K & 4 & $221,95^{* *}$ & $159,66^{* *}$ & $1,21^{\mathrm{ns}}$ & $15,16^{\mathrm{ns}}$ & $9,86^{\mathrm{ns}}$ \\
\hline $\mathrm{N} \times \mathrm{K}$ & 4 & $10,08^{\text {ns }}$ & $99,80^{* *}$ & $0,55^{\mathrm{ns}}$ & $9,66^{\mathrm{ns}}$ & $36,20^{* *}$ \\
\hline Bloco & 2 & $431,03^{* *}$ & $37,20^{\mathrm{ns}}$ & $3,03^{\mathrm{ns}}$ & $207,70^{* *}$ & $4,43^{\mathrm{ns}}$ \\
\hline Resíduo & 18 & 42,62 & 10,94 & 0,99 & 15,88 & 6,65 \\
\hline CV (\%) & - & 7,22 & 2,28 & 16,45 & 10,92 & 8,61 \\
\hline $\mathrm{N}$ & - & \multicolumn{2}{|c|}{----- Médias (cm) ----- } & \multicolumn{2}{|c|}{------- Médias ------- } & Médias $(\mathrm{mm})$ \\
\hline Com & - & 88,47 a & 146,6 a & $5,67 \mathrm{~b}$ & 39,67 a & 29,93 a \\
\hline Sem & - & 92,47 a & $143,4 \mathrm{~b}$ & $6,47 \mathrm{a}$ & $33,33 \mathrm{~b}$ & $30,00 \mathrm{a}$ \\
\hline DMS & - & 5,00 & 2,54 & 0,76 & 3,06 & 1,98 \\
\hline
\end{tabular}

** Significativo entre si a 0,01\% de probabilidade pelo teste F; * Significativo a 0,05\% de probabilidade pelo teste F; ns Não significativo a 0,05 de probabilidade pelo teste F; Médias seguidas de mesma letra nas colunas não diferem estatisticamente a 0,05\% de probabilidade, pelo teste Tukey.

de irrigação e adubação, Freitas et al. (2013) afirma que quanto maior a dose de nitrogênio, maior o NF e NP. O NF ter sido superior nos tratamentos sem N pode ser explicado que, devido o CF ter sido superior para os tratamentos com $\mathrm{N}$, a planta investiu mais nesta variável, do que, gastando mais energia para aumentar o NF.

Realizando o desdobramento da interação $\mathrm{N} \times \mathrm{K}$ para a variável CF aos 150 DAC, observa-se que dentro dos níveis de potássio, somente na D240 houve influência da adubação nitrogenada, na qual o comprimento de folha foi em média $146,7 \mathrm{~cm}$ para os tratamentos que receberam $\mathrm{N}$ e em média $139 \mathrm{~cm}$ para os tratamentos que não receberam (Figura 3A). Na Figura 3B nota-se que a adubação nitrogenada influenciou o DC nas duas maiores doses de $\mathrm{K}$, de forma que os resultados encontrados foram divergentes, já que na D180 o melhor tratamento foi sem N e na D240 foi com N.
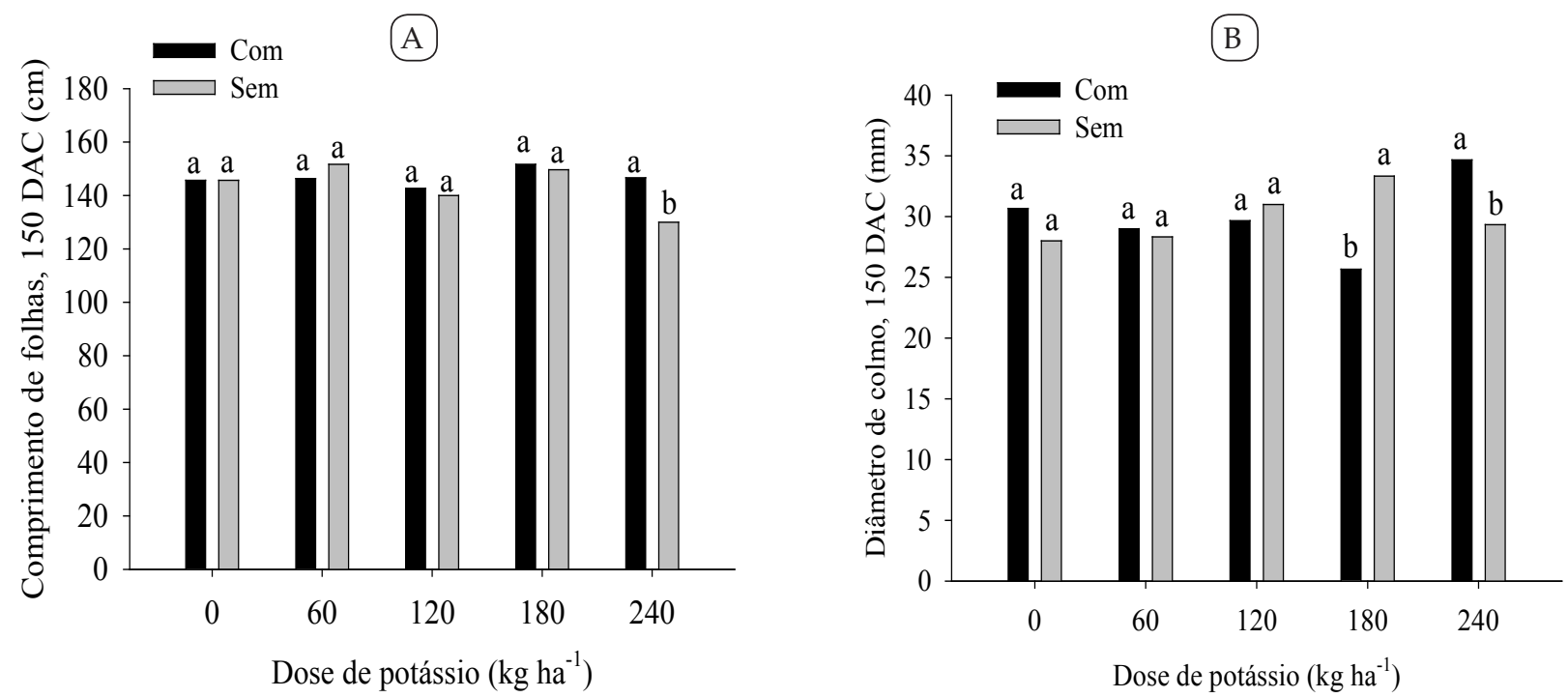

Figura 3 - Comprimento de folha (A) Diâmetro de colmos da cana-de-açúcar (B) em função da adubação nitrogenada, dentro de cada dose de potássio. 
As variáveis NF e DC foram influenciadas pelo fator isolado de adubação nitrogenada aos 190 DAC, observa-se que para NF os tratamentos se mantiveram iguais aos encontrados nos 150 DAC. Para DC os tratamentos com a adubação nitrogenada, foram superiores, obtivendo uma diferença média de 2,66 mm, sugerindo que o resultado divergente encontrado na D180 aos 150 DAC foi um caso atípico, que não expressa a realidade, ficando claro o benefício que $\mathrm{N}$ promove ao diâmetro do colmo da cana-de-açúcar. Esse resultado é comprovado com as demais avaliações, pois em todas as datas o DC foi superior quando se aplica N (Quadros 2 a 4 e 5). Os resultados encontrados nesse estudo para o diâmetro de colmo vai contra os encontrados por Da Silva et al. (2014), que ao estudarem em um Latossolo Vermelho Distroférrico o efeito do $\mathrm{N}$ em cana-de-açúcar (planta) notou que a cultura não respondeu a adubação nitrogenada. Porém corrobora com Uribe et al. (2013) que constatou o acréscimo de $1 \mathrm{~mm}$ no DC para cada aumento de dose de $\mathrm{N}$ em soqueiras de cana-de-açúcar. Divergências em resultados relacionados à adubação nitrogenada são bastantes comuns quando não são especificados o ciclo de cultivo, pois sabe-se que a respostas deste nutriente são mais frequentes em soqueiras do que no ciclo de planta (Urquiaga et al., 2012; Teodoro et al., 2013; Schultz et al., 2015).
Da mesma forma aos 150 DAC a altura de planta aos 190 DAC foi influenciada somente pela adubação potássica, porém nenhuma das equações estudas se ajustaram. No mesmo período o diâmetro de colmo também foi influenciado pelas doses de K. Já para $C F$, houve significância estatística para interação entre os fatores (Quadro 3), no qual para o desdobramento em função das doses de potássio dentro do fator com e sem adubação nitrogenada, não houve ajuste para as equações estudadas.

Quanto ao comprimento de folha nota-se na Figura $4 \mathrm{~A}$ que o tratamento com $\mathrm{N}$ foi superior nas D0 e D180 de K e estatisticamente igual nas demais doses. Este resultado também confirma o benefício que o nitrogênio proporciona para o $\mathrm{CF}$ das folhas de cana-de-açúcar. Analisando somente o N isolado nota-se valores superiores com a aplicação do nutriente desde os 150 aos 230 DAC, de modo que aos $270 \mathrm{DAC}$ não existe diferença para o $\mathrm{CF}$, isso ocorre devido ao fim do ciclo da cultura que utiliza suas reservas nutricionais prioritariamente para o desenvolvimento dos colmos, não mais das folhas como no início e meio do ciclo. O comprimento da folha associado ao número de folhas são parâmetros que permitem avaliar a produtividade da cultura, pois fazem parte dos elementos que formam o aparato fotossintético (Magalhães, 1979).

Quadro 3 - Análise de variância para altura de planta (AP), comprimento de folha (CF), número de folhas (NF) e diâmetro do colmo (DC) da cana-de-açúcar, aos 190 dias após o corte (DAC), submetida a diferentes tratamentos com e sem nitrogênio e a diferentes doses de adubação potássica

\begin{tabular}{|c|c|c|c|c|c|}
\hline \multirow{2}{*}{ FV } & \multirow{2}{*}{ GL } & \multicolumn{4}{|c|}{ Quadrado médio } \\
\hline & & AP & $\mathrm{CF}$ & NF & DC \\
\hline $\mathrm{N}$ & 1 & $0,01^{\mathrm{ns}}$ & $1116,30^{* *}$ & $9,63^{* *}$ & $53,33^{* *}$ \\
\hline K & 4 & $379,11^{*}$ & $102,88^{\text {ns }}$ & $0,88^{\text {ns }}$ & $13,21^{*}$ \\
\hline $\mathrm{N} \times \mathrm{K}$ & 4 & $54,08^{\mathrm{ns}}$ & $206,38^{*}$ & $0,55^{\mathrm{ns}}$ & $6,58^{\mathrm{ns}}$ \\
\hline Bloco & 2 & $253,63^{\text {ns }}$ & $56,23^{\mathrm{ns}}$ & $3,60^{* *}$ & $12,23^{\mathrm{ns}}$ \\
\hline Resíduo & 18 & 124,74 & 49,08 & 0,56 & 3,82 \\
\hline CV $(\%)$ & - & 7,89 & 4,65 & 8,43 & 6,53 \\
\hline $\mathrm{N}$ & - & \multicolumn{2}{|c|}{---------- Médias (cm) ---------- } & Médias & Médias (mm) \\
\hline Com & - & $141,53 \mathrm{a}$ & 156,67 a & $8,33 \mathrm{~b}$ & 31,26 a \\
\hline Sem & - & $141,53 \mathrm{a}$ & $144,47 \mathrm{~b}$ & 9,46 a & $28,6 \mathrm{~b}$ \\
\hline DMS & - & 8,57 & 5,37 & 0,57 & 1,50 \\
\hline
\end{tabular}

** Significativo entre si a 0,01\% de probabilidade pelo teste $\mathrm{F}$; * Significativo a 0,05\% de probabilidade pelo teste $\mathrm{F}$; ns Não significativo a 0,05 de probabilidade pelo teste F; Médias seguidas de mesma letra nas colunas não diferem estatisticamente a 0,05\% de probabilidade, pelo teste Tukey. 
(A)

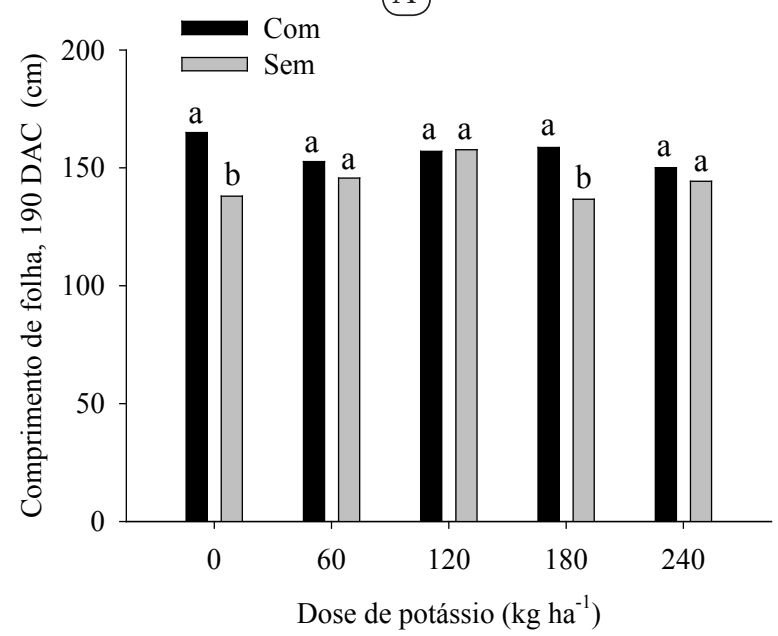

B

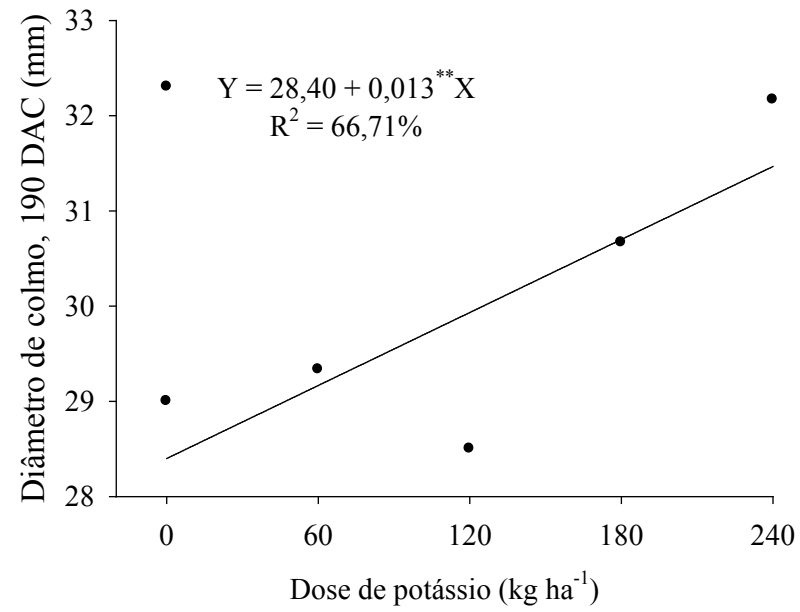

Figura 4 - Comprimento de folha em função da adubação nitrogenada, dentro de cada dose de potássio (A); Diâmetro de colmo em função das doses de potássio (B).

Ao analisar o DC aos 190 DAC em relação as doses de $\mathrm{K}$, nota-se um comportamento linear crescente, ou seja, a cada aumento nas doses de potássio o DC obteve um incremento. O menor valor encontrado para o DC foi para a ausência de $\mathrm{K}$ no valor $28,4 \mathrm{~mm}$ e o maior valor foi para a D240, no valor de $31,52 \mathrm{~mm}$ culminando em uma diferença de $3,12 \mathrm{~mm}$. Houve um incremento de $2,74 \%$ no DC, para cada dose de $\mathrm{K}$ acrescida (Figura $4 \mathrm{~B}$ ).
Observando o Quadro 4 (230 DAC), nota se que somente a variável CF foi estatisticamente influenciada pelo fator $\mathrm{N}$, na qual houve um aumento médio de $10,9 \mathrm{~cm}$ no CF das plantas submetidas a adubação nitrogenada em relação as plantas sem a presença de $\mathrm{N}$. As doses de $\mathrm{K}$ isoladas influenciaram significativamente as variáveis $\mathrm{AP}$ e $\mathrm{CF}$, mas para a variável AP as equações estudadas não se ajustaram, igualando as datas de avaliação 150 e 190 DAC. Na interação entre os fatores N x K,

Quadro 4 - Análise de variância para altura de planta (AP), comprimento de folha (CF), comprimento médio do colmo (CMC) e diâmetro do colmo (DC) da cana-de-açúcar, aos 230 dias após o corte (DAC), submetida a diferentes tratamentos com e sem nitrogênio e a diferentes doses de adubação potássica

\begin{tabular}{|c|c|c|c|c|c|}
\hline \multirow{2}{*}{ FV } & \multirow{2}{*}{ GL } & \multicolumn{4}{|c|}{ Quadrado médio } \\
\hline & & AP & $\mathrm{CF}$ & CMC & DC \\
\hline $\mathrm{N}$ & 1 & $456,30^{\text {ns }}$ & $885,63^{* *}$ & $6,53^{\mathrm{ns}}$ & $22,53^{*}$ \\
\hline K & 4 & $1486,30^{* *}$ & $431,16^{* *}$ & $4,21^{\mathrm{ns}}$ & $20,11^{* *}$ \\
\hline $\mathrm{N} \times \mathrm{K}$ & 4 & $41,30^{\mathrm{ns}}$ & $162,96^{\mathrm{ns}}$ & $8,28^{*}$ & $21,61^{* *}$ \\
\hline Bloco & 2 & $36,43^{\text {ns }}$ & $590,83^{* *}$ & $3,60^{\text {ns }}$ & $2,23^{\mathrm{ns}}$ \\
\hline Resíduo & 18 & 146,32 & 61,79 & 2,08 & 3,75 \\
\hline CV $(\%)$ & - & 6,62 & 4,89 & 16,78 & 6,49 \\
\hline $\mathrm{N}$ & - & \multicolumn{3}{|c|}{ 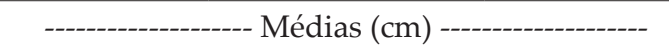 } & Médias (mm) \\
\hline Com & - & 186,67 a & 166,27 a & 9,07 a & $30,73 \mathrm{a}$ \\
\hline Sem & - & 178,87 a & $155,40 \mathrm{~b}$ & $8,13 \mathrm{a}$ & $29,00 \mathrm{~b}$ \\
\hline DMS & - & 9,28 & 6,03 & 1,11 & 1,48 \\
\hline
\end{tabular}

** Significativo entre si a 0,01\% de probabilidade pelo teste $\mathrm{F}$; * Significativo a 0,05\% de probabilidade pelo teste $\mathrm{F}$; ns Não significativo a 0,05 de probabilidade pelo teste F; Médias seguidas de mesma letra nas colunas não diferem estatisticamente a $0,05 \%$ de probabilidade, pelo teste Tukey. 
houve diferença significativa para o comprimento médio do colmo e diâmetro de colmo, sendo que, no desdobramento para essas variáveis, em função do K dentro das adubações com e sem $\mathrm{N}$, nenhuma das equações estudadas se ajustaram.

Aos 230 DAC, o comportamento da variável CF em relação as doses de potássio foi o quadrático, de acordo com a Figura 5A. Nota se que houve um acréscimo no CF até a dose de $108 \mathrm{~kg} \mathrm{ha}^{-1}$ de $\mathrm{K}$, a partir desse ponto a adubação potássica passa a influenciar de forma negativa o $\mathrm{CF}$, nesta dose de adubação o CF atingiu o ponto máximo, sendo esse valor de $169 \mathrm{~cm}$. Apesar deste resultado, foi notado que nas condições atuais de estudo o comprimento de folha e a altura de planta não foram bem representados pelas equações lineares e quadráticas, já que na maioria das datas de avaliações houve a diferença para o fator, porém as equações não se ajustaram.

$\mathrm{O}$ desdobramento da interação $\mathrm{N}$ dentro de cada nível de K para a variável CMC aos 230 DAC é observado na Figura 5B. Pode-se se observar, que ao desdobrar a adubação nitrogenada para cada dose de potássio, somente onde não houve aplicação de potássio o nitrogênio influenciou, onde o CMC obteve um valor de 10,3 e $6 \mathrm{~cm}$, para com e sem $\mathrm{N}$, respectivamente. Já o diâmetro de colmo aos $230 \mathrm{DAC}$ foi superior na presença de $\mathrm{N}$ dentro do nível de 240D (Figura 5C), se igualando as demais datas de avaliação.
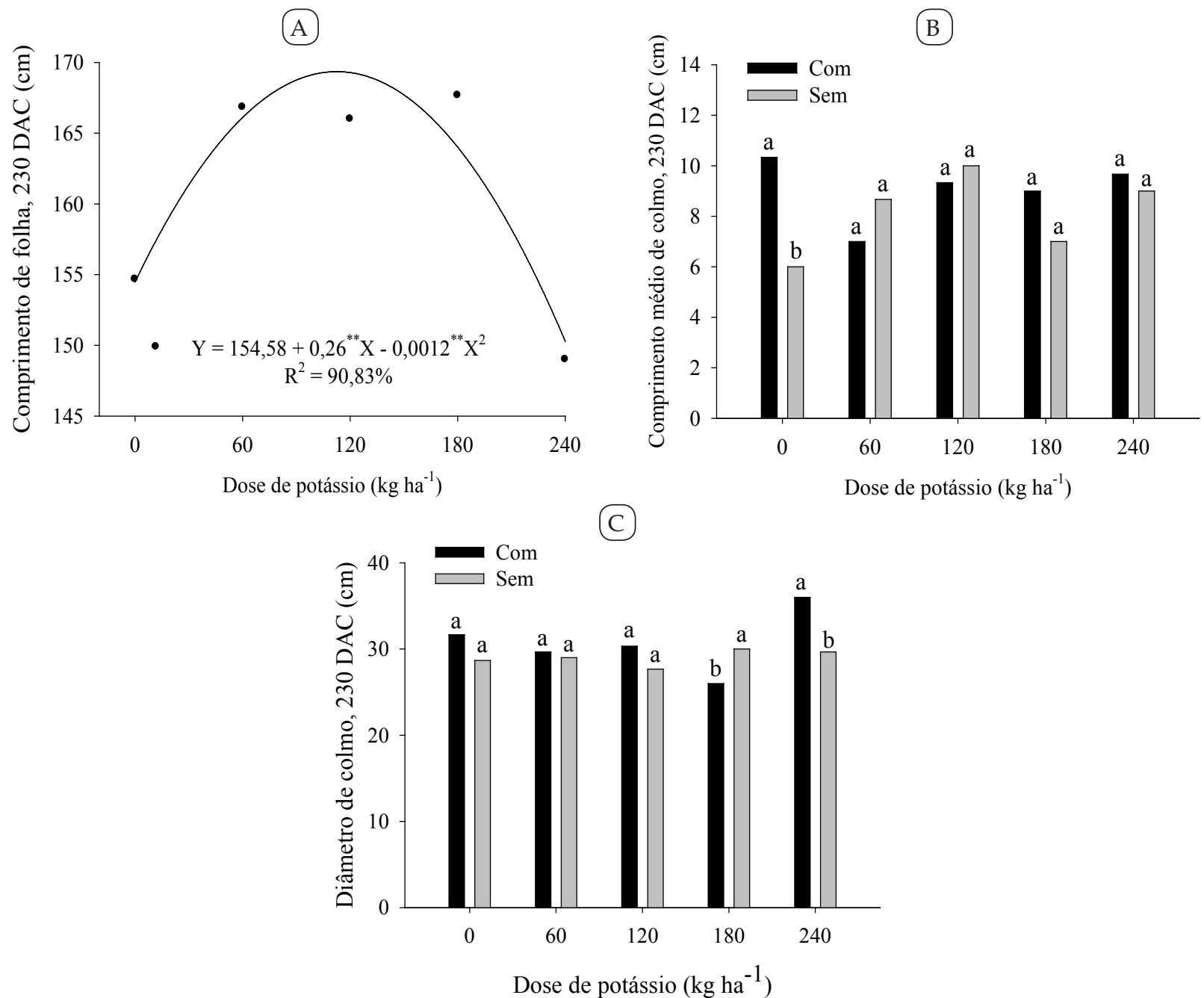

Figura 5 - Comprimento de folha em função de doses de potássio (A); Comprimento médio do colmo em função da adubação nitrogenada, dentro de cada dose de potássio (B); Diâmetro de colmo em função da adubação nitrogenada, dentro de cada dose de potássio (C). 
Quadro 5 - Análise de variância para altura de planta (AP), comprimento médio do colmo(CMC) e diâmetro do colmo (DC) da cana-de-açúcar, aos 270 dias após o corte (DAC), submetida a diferentes tratamentos com e sem nitrogênio e a diferentes doses de adubação potássica

\begin{tabular}{ccccc}
\hline \multirow{2}{*}{ FV } & GL & \multicolumn{3}{c}{ Quadrado médio } \\
\cline { 3 - 5 } & 1 & AP & CMC & DC \\
\hline N & 4 & $2613,33^{*}$ & $2,13^{\text {ns }}$ & $45,63^{* *}$ \\
K & $4250,41^{* *}$ & $3,21^{*}$ & $15,21^{*}$ \\
N x K & 4 & $3738,75^{* *}$ & $4,05^{*}$ & $11,55^{*}$ \\
Bloco & 2 & $203,23^{\text {ns }}$ & $2,53^{\text {ns }}$ & $7,60^{\text {ns }}$ \\
Resíduo & 18 & 462,78 & 1,08 & 3,93 \\
\hline CV $(\%)$ & - & 9,33 & 10,37 & 6,59 \\
\hline N & - & ------------ Médias $(\mathrm{cm})$ & ------------ & Médias $(\mathrm{mm})$ \\
\hline Com & - & 240,00 a & 10,33 a & 31,33 a \\
Sem & - & $221,33 \mathrm{~b}$ & 9,80 a & $28,86 \mathrm{~b}$ \\
\hline DMS & - & 16,50 & 0,80 & 1,52 \\
\hline
\end{tabular}

** Significativo entre si a 0,01 de probabilidade pelo teste F; * Significativo a 0,05 de probabilidade pelo teste F; ns Não significativo a 0,05 de probabilidade pelo teste $\mathrm{F}$; Médias seguidas de mesma letra nas colunas não diferem estatisticamente a 0,05 de probabilidade, pelo teste Tukey.

No Quadro 5 é observado o resumo da análise de variância aos $270 \mathrm{DAC}$ para as variáveis $\mathrm{AP}, \mathrm{CMC}$ e DC, onde todas elas, foram influenciadas estatisticamente pela interação $\mathrm{N} \times \mathrm{K}$, mas ao realizar o desdobramento desse fator para cada variável analisada, observa-se em função das doses de potássio dentro de cada nível de nitrogênio que para o CMC as equações estudadas não se ajustaram (Figura 6). Para AP houve ajuste apenas no nível sem N (Figura 6B) e para DC a equação se ajustou somente no nível com N (Figura 6D).

Considerando todas as datas de avaliações o N influenciou a altura de planta somente aos 270 , de forma associada com o K. No desdobramento da interação $\mathrm{N} \times \mathrm{K}$ para a variável (Figura 6A e 6B), o $\mathrm{N}$ proporcionou incremento na AP somente quando não houve adubação potássica (Figura 6A). Já o potássio proporcionou incremento na $\mathrm{AP}$ até dose estimada de $182,5 \mathrm{~kg} \mathrm{ha}^{-1}$, quando associado sem aplicação de $\mathrm{N}$ (Figura 6B). Os resultados para a altura de planta foram similares aos encontrados para o comprimento médio de colmos, e também corroboram com Flores et al. (2013), pois ao estudarem o potássio no desenvolvimento de cana-de-açúcar, constataram um incremento na AP até a dose de $195 \mathrm{~kg} \mathrm{ha}^{-1}$, onde foi encontrado valor máximo de $274 \mathrm{~cm}$, ficando próximo dos $277,45 \mathrm{~cm}$ alcançados no estudo em questão pela D182,5.
O nitrogênio incrementou o diâmetro de colmo aos 270 DAC nas D120 e D240 (Figura 6C), demonstrado a interação entres esses nutrientes para um bom desenvolvimento do DC. Na Figura 6D nota-se que com aplicação de $\mathrm{N}$ o diâmetro de colmo alcançado pela D0 é de $31,56 \mathrm{~mm}$, sendo superior aos observados nas D60 e D120, e se igualando ao alcançado pela D180. Com aumento das doses a partir da D180 de K, os incrementos são portanto superiores aos encontrados no D0, sendo esses valores superiores a 31,56 $\mathrm{mm}$. Estes resultados foram de acordo com os encontrados por Uchôa et al. (2009), que estudando diferentes doses de $\mathrm{K}$ em seis diferentes cultivares de cana-de-açúcar notaram que o diâmetro de colmo máximo foram alcançados por doses entre 216 e $273 \mathrm{~kg} \mathrm{ha}^{-1}$.

Na Figura 6E nota-se o desdobramento da interação $\mathrm{N} \times \mathrm{K}$ para o comprimento médio dos colmos aos $270 \mathrm{DAC}$, sendo que o $\mathrm{N}$ influenciou significativamente esta variável somente nas doses de 0 e $60 \mathrm{~kg} \mathrm{ha}^{-1}$. O nitrogênio foi superior somente sem aplicação de K, se igualando ao CMC 230, evidenciando que nessas condições de estudos, quando se aplica $60 \mathrm{~kg} \mathrm{ha}^{-1}$ de $\mathrm{K}$ ou mais, não existe a necessidade de adubação nitrogenada visando incremento no comprimento médio dos colmos e quando não houver aplicação de $\mathrm{K}$ o nitrogênio propicia grandes incrementos para esta variável. 
(A)

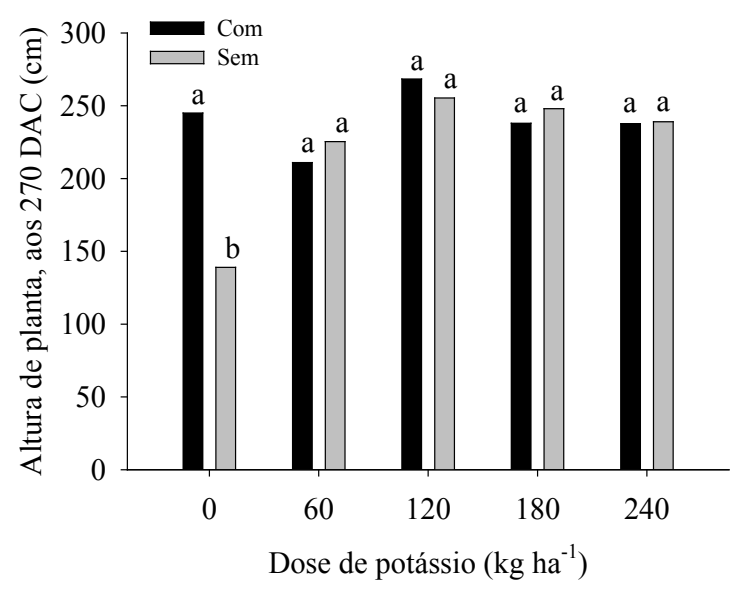

(C)

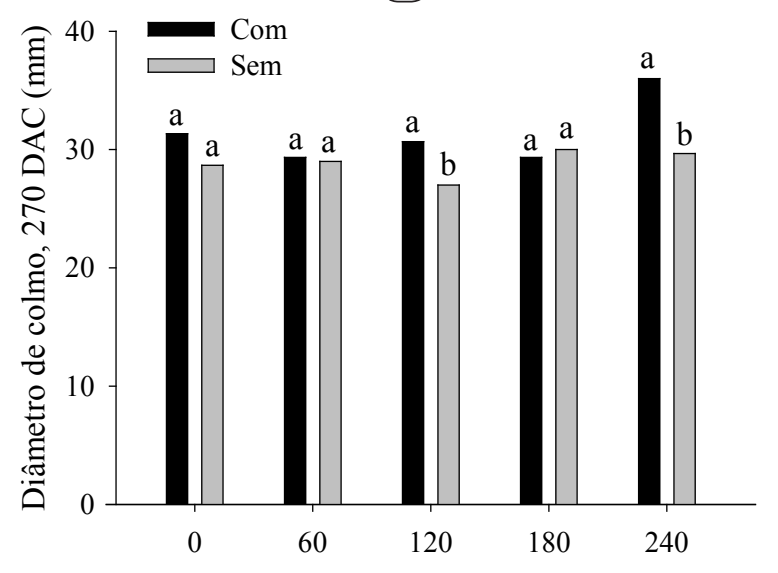

Dose de potássio $\left(\mathrm{kg} \mathrm{ha}^{-1}\right)$

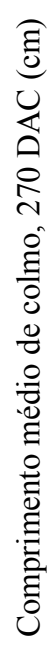

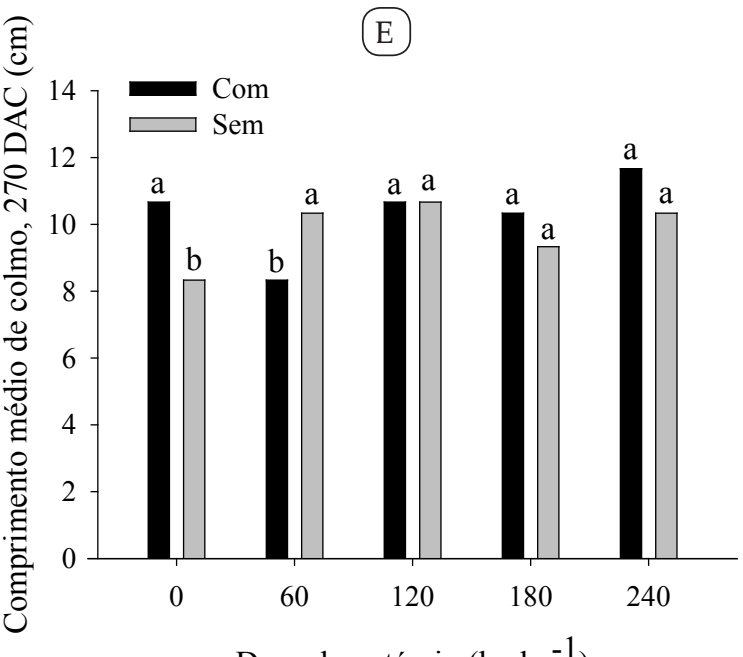

Dose de potássio $\left(\mathrm{kg} \mathrm{ha}^{-1}\right)$
(B)

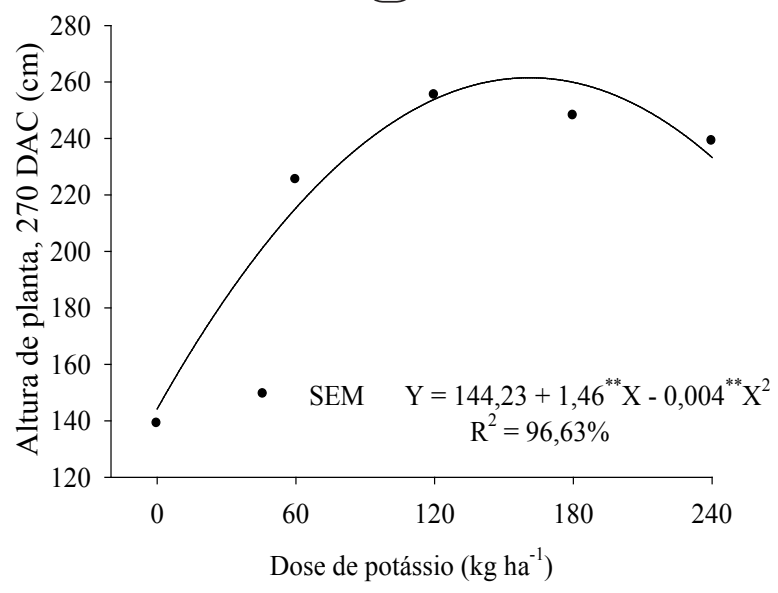

(D)

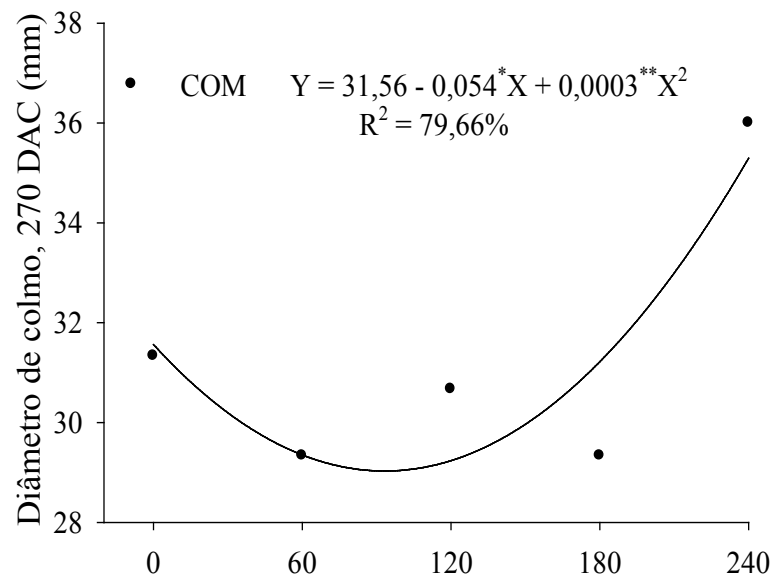

Dose de potássio $\left(\mathrm{kg} \mathrm{ha}^{-1}\right)$

Figura 6 - Altura de planta em função da adubação nitrogenada, dentro de cada dose de potássio (A); Altura de planta em função da adubação potássica dentro de cada nível de nitrogênio (B); Diâmetro de colmo em função da adubação nitrogenada, dentro de cada dose de potássio (C); Diâmetro de colmo em função da adubação potássica dentro de cada nível de nitrogênio (D); Diâmetro médio do colmo em função da adubação nitrogenada, dentro de cada dose de potássio (E). 
Vale ressaltar que mesmo com teores elevados de matéria orgânica no solo a adubação nitrogenada e potássica influenciaram tanto em conjunto quanto isoladas o crescimento da cana-de-açúcar. Demonstrando a necessidade por nitrogênio e potássio que a cultura possui, bem como os níveis ideais de adubações para esses nutrientes visando incremento para diferentes variáveis biométricas, mesmo com atual sistema de cultivo da cana-de-açúcar, que presa pela colheita mecanizada e manutenção da palhada no solo.

\section{CONCLUSÕES}

A aplicação de nitrogênio beneficiou o comprimento das folhas, porém limitou a quantidade de folhas por planta. Já quanto ao comprimento médio dos colmos e altura de plantas o nitrogênio foi responsável por incrementos somente quando não houve adubação potássica. O potássio proporcionou incrementos para altura de planta quando não houve adubação com $\mathrm{N}$, enquanto para o diâmetro de colmo a dose de $240 \mathrm{~kg} \mathrm{ha}^{-1}$ obteve o maior valor quando associado à adubação nitrogenada.

\section{AGRADECIMENTOS}

Ao CNPq (Conselho Nacional de Desenvolvimento Científico e Tecnológico, Brasil), pelo financiamento do estudo, a CAPES (Coordenação de Aperfeiçoamento de Pessoal de Nível Superior, Brasil), à FAPEG (Fundação de Apoio à Pesquisa do Estado de Goiás), à FINEP e ao Instituto Federal Goiano - Campus Rio Verde.

\section{REFERÊNCIAS BIBLIOGRÁFICAS}

Aquino, A.B. (1993) - Recomendações de adubação e calagem para o estado do Ceará. UFC, Fortaleza. 248 p.

Castro Neto, P. (1982) - Notas de aula prática do curso de agrometeorologia. Lavras, ESAL, 45 p.

Conab (2016) - Companhia Nacional de Abastecimento. Acompanhamento da safra brasileira de cana. Terceiro levantamento, Brasília, vol. 2, n. 3, p. 1-65.

Christoffoleti, P.J.; Carvalho, S.J.P. de; López-Ovejero, R.F.; Nicolai, M.; Hidalgo, E. \& Silva, J.E. da (2007) - Conservation of natural resources in Brazilian agriculture: implications on weed biology and management. Crop Protection, vol. 26, n. 3, p. 383-389. http://dx.doi.org/10.1016/j.cropro.2005.06.013

Da Silva, N.F.; Cunha, F.N.; de Oliveira, R.C.; de Freitas Moura, L.M.; de Campos Bastos, F.J. \& Teixeira, M.B. (2014) - Crescimento da cana-de-açúcar sob aplicação de nitrogênio via gotejamento subsuperficial. Revista Brasileira de Agricultura Irrigada, vol. 8, n. 1, p. 1-11. http://dx.doi.org/10.7127/rbai.v8n100188

De Souza, Z.M.; de Mello Prado, R. Paixão, A.C.S. \& Cesarin, L.G. (2005) - Sistemas de colheita e manejo da palhada de cana-de-açúcar. Pesquisa Agropecuária Brasileira, vol. 40, n. 3, p. 271-278. http://dx.doi.org/10.1590/ $\underline{\text { S0100-204X2005000300011 }}$

Devos, K.M. (2010) - Grass genome organization and evolution. Current Opinion in Plant Biology. vol. 13, n. 2, p. 139-145. http://dx.doi.org/10.1016/j.pbi.2009.12.005

Ferreira, D.F. (2011) - Sisvar: a computer statistical analysis system. Ciência e Agrotecnologia, vol. 35, n. 6, p. 1039-1042. http://dx.doi.org/10.1590/S1413-70542011000600001

Flores, R.A.; de Mello Prado, R.; Politi, L. S. \& de Almeida, T.B.F. (2012) - Potássio no desenvolvimento inicial da soqueira de cana crua. Pesquisa Agropecuária Tropical, vol. 42, n. 1, p. 10-1590. http://dx.doi.org/10.1590/ $\underline{\text { S1983-40632012000100015 }}$

Freitas, E.L.; Fernandes, A.R.; da Costa, C.; Rolim M.M.; da Silva, M.M.; França e Silva, E.F.; Dantas, M.S.M. \& Cabral, E.F. (2013) - Avaliação de parâmetros biométricos da cana-de-açúcar em função de diferentes níveis de irrigação e adubação. In: XIII jornada de ensino, pesquisa e extensão. Recife, Brasil.

Franco, H.C.J. (2008) - Eficiência agronômica da adubação nitrogenada de cana-planta. Tese de Doutoramento. Escola Superior de Agricultura “Luiz de Queiroz”, Universidade de São Paulo, Piracicaba, Brasil. 112 p. 
Gava, G.J.C.; Trivelin, P.C.O.; Oliveira, M.W. \& Penatti, C.P. (2001) - Crescimento e acúmulo de N em cana-de-açúcar cultivada em solo coberto com palhada. Pesquisa Agropecuária Brasileira, vol. 36, n. 11, p. 1347-1354. http://dx.doi.org/10.1590/S0100-204X2001001100004

Inman-Bamber, N.G.; Muchow, R.C. \& Robertson, M.J. (2002) - Dry partitioning of sugarcane in Australia and South Africa. Field Crops Research, vol. 76, n. 1, p. 71-84. http://dx.doi.org/10.1016/S0378-4290(02)00044-8

Kajihara, D.; Godoy, F de; Hamaji, T.A.; Blanco, S.R.; Sluys, M.A.V. \& Rossi, M. (2012) - Functional characterization of sugarcane mustang domesticated transposases and comparative diversity in sugarcane, rice, maize and sorghum. Genetics and Molecular Biology, vol. 35, n. 3, p. 632-639. http://dx.doi.org/10.1590/ $\underline{\text { S1415-47572012005000038 }}$

Magalhães, A.C.N. (1979) - Análise quantitativa do crescimento. In: FERRI, M. G. Fisiologia Vegetal. EPU/ EDUSP, São Paulo, vol. 1, p. 331-350.

Oliveira, E.C.A. (2011) - Balanço nutricional da cana-de-açúcar relacionada a adubação nitrogenada. Tese de Doutoramento. Escola Superior de Agricultura “Luiz de Queiroz", Universidade de São Paulo, Piracicaba, Brasil. 213 p.

Robertson, M.J.; Wood, A.W. \& Muchow, R.C. (1996) - Growth of sugarcane under high input conditions in tropical Australia: I. radiation use, biomass accumulation and partitioning. Field Crops Research, vol. 48, n. 1, p. 11-25. http://dx.doi.org/10.1016/0378-4290(96)00041-X

Schultz, N; Reis, V.M. \& Urquiaga, S. (2015) - Resposta da cana-de-açúcar à adubação nitrogenada: fontes nitrogenadas, formas de aplicação, épocas de aplicação e efeito varietal. Embrapa Agrobiologia, Seropédica. Documentos $52 \mathrm{p}$.

Solos. (2013) - Sistema brasileiro de classificação de solos. Centro Nacional de Pesquisa de Solos, Rio de Janeiro, RJ, Brasil. 306 p.

Teodoro I.T.; Neto J.D.; Souza J.L.; Lira, G.B.; Brito, K.S.; Sá, L.A.; Santos, M.A.L. \& Sarmento, P.L.V.S. (2013) - Isoquantas de Produtividade da Cana-de-açúcar em Função de Níveis de Irrigação e Adubação Nitrogenada. Irriga, vol. 18, n. 3, p. 387-401. http://dx.doi.org/10.15809/irriga.2013v18n3p387

Uchôa, S.C.P.; Júnior, H.D.O.A.; Alves, J.M.A.; Melo, V.F. \& Ferreira, G.B. (2009) - Resposta de seis variedades de cana-de-açúcar a doses de potássio em ecossistema de cerrado de Roraima. Revista Ciência Agronômica, vol. 40, n. 4, p. 505-513.

Uribe, R.A.; Gava, G.J.D.C.; Saad, J.C. \& Kölln, O.T. (2013) - Ratoon sugarcane yield integrated drip-irrigation and nitrogen fertilization. Engenharia Agrícola, vol. 33, n. 6, p. 1124-1133. http://dx.doi.org/10.1590/ $\underline{\text { S0100-69162013000600005 }}$

Urquiaga, S.; Xavier, R.P.; Morais, R.F. de; Batista, R.B.; Schultz, N.; Leite, J.M.; Sá, J. M.; Barbosa, K.; Resende, A.S. de; Alves, B.J.R. \& Boddey, R.M. (2012) - Evidence from field nitrogen balance and ${ }^{15} \mathrm{~N}$ natural abundance data for the contribution of biological $\mathrm{N}_{2}$ fixation to Brazilian sugarcane varieties. Plant and Soil, vol. 356, n. 1, p. 5-21. http://dx.doi.org/10.1007/s11104-011-1016-3

Vieira-Megda, M.X.; Mariano, E.; Leite, J.M.; Franco, H.C.J.; Vitti, A.C.; Megda, M.M.; Trivelin, P.C.O. (2015) Contribution of fertilizer nitrogen to the total nitrogen extracted by sugarcane under Brazilian field conditions. Nutrient Cycling in Agroecosystems, vol. 101, n. 2, p. 241-257. http://dx.doi.org/10.1007/s10705-015-9676-7 